\title{
Battery internal resistance estimation using a battery balancing system based on switched capacitors
}

\author{
Cristina Gonzalez Moral ${ }^{\dagger \dagger}$, Diego Fernández Laborda ${ }^{\dagger}$, Lidia Sánchez Alonso ${ }^{\dagger}$, Juan Manuel Guerrero ${ }^{\dagger}$, Daniel \\ Fernandez $z^{\dagger}$, Carlos Rivas ${ }^{\dagger \dagger}$ and David Díaz Reigosa ${ }^{\dagger}$ \\ $\uparrow$ University of Oviedo. Dept. of Elect. Computer \& \\ System Engineering, Gijón, 33204, Spain \\ $\dagger \dagger$ Electrotécnica Industrial y Naval, S.L. (ELINSA), \\ 15008, A Coruña, Spain \\ cgonzalez@elinsa.org,dflaborda@uniovi.es, uo250173@uniovi.es, guerrero@uniovi.es, fernandezalodaniel@uniovi.es, \\ crivas@elinsa.org,diazdavid@uniovi.es
}

\begin{abstract}
Battery Management Systems (BMS) are key components in battery storage systems in order to guarantee their safe operation and improve their performance, reliability and efficiency. BMS monitor critical parameters in the battery as state-of-charge (SOC), state-of-health (SOH) or temperature. Direct measure of SOC or SOH is not possible, while temperature, on the other hand, can be measure with different types of sensors. These sensors, although cost-effective, raise concerns regarding cabling, signal conditioning and acquisition systems, increasing cost, complexity and decreasing reliability. The internal resistor of the battery has already been successfully used to estimate these parameters. BMS can also include the function of balancing (equalizing) cells of a battery pack. Among all available equalizing systems, those based on switched capacitors are interesting due to their simplicity and easy scalability. This paper proposes an internal resistance (IR) estimation method for $\mathrm{LiFePO}_{4}$ batteries using signals naturally produced by a switched capacitor equalizer (SCE). The IR will be used to estimate the battery temperature. It will be shown that the method can operate online and without interfering with the regular operation of the SCE.
\end{abstract}

Keywords - LFP batteries, switched-capacitor equalizer, internal resistance estimation, temperature estimation.

\section{INTRODUCTION}

The use of battery-based Energy Storage Systems (ESS) has highly increased in the last decades [2]. They can be found in a broad range of applications, such as electric vehicles (EV) [2], smart grids [3], aerospace applications [4] and all kind of small appliances applications as mobile devices [5].

There is a wide variety of rechargeable batteries (secondary batteries) technologies that could be used for ESS, as nickel-cadmium (NiCd), $\mathrm{Pb}$-acid or lithium-ion (Li-ion). Among these, $\mathrm{Li}$-ion batteries are one of the most appealing batteries for high capacity ESS due to their high energy density, good temperature operation range, low selfdischarge and high cell voltage compared with $\mathrm{NiCd}$ or $\mathrm{Pb}$ acid [5].

Since the cell voltage and/or current in any of these cases is low compared with typical industrial requirements, battery packs are built stacking cells in series and/or parallel configurations [2]. Manufacturing tolerances, temperature differences, cell distribution inside the pack (which affects the battery temperature), among other reasons, result in voltage imbalances among cells during normal pack

1 This work was supported in part by the Research, Technological Development and Innovation Programs of the Spanish Ministry Economy and Competitiveness, under grant MINECO-17-ENE2016-80047-R, by the operation. These imbalances accelerate aging of cells and result in an increase of the internal battery resistance and in a decrease of its capacity. Mismatches in voltage among cells also increase the internal battery temperature, decreasing therefore operation safety [6], [7]. Active materials in the Liion Batteries (LIB) can be potentially damaged in the case of overvoltage or undervoltage [8], [9]. For all these reasons, BMS are needed to increase the overall safety of the system: monitor critical parameters as temperature, $\mathrm{SOC}$ or $\mathrm{SOH}$ [3][11], control operational conditions and cell balancing, extend the life of the battery and ensure a safe range of operation for all the cells forming the pack [10]. Batteries' temperature can be directly measured using temperature sensors [12]. These sensors, although cheap, raise concerns regarding cabling, signal conditioning and acquisition systems, increasing cost, system complexity and the number of elements susceptible of failure [13], [14]. As an alternative, batteries' temperature can be estimated. Temperature estimation methods based on the dependency of the battery IR with its temperature are the most popular [12]-[15]. On the other hand, since SOC and SOH cannot be directly measured, estimation methods must be implemented [10]. Several methods to estimate battery critical parameters can be found in the literature, one of the most popular being based on the battery IR [16].

This paper [1] proposes an on-line battery IR estimation method, i.e. during cell balancing, for switched capacitor equalizers (SCEs). The IR of the battery is estimated using signals produced by the SCE regular operation; the IR will be used for cell temperature estimation. The article is organized as follows: basis of SCEs are presented in section II; electrical modeling of batteries are discussed in section III; the proposed method for battery IR estimation is presented in section IV; simulations and experimental results are shown in sections $\mathrm{V}$ and VI respectively; conclusions are finally presented in section VII.

\section{SWITCHED-CAPACITOR EQUALIZER}

This section presents a brief review of different equalizing methodologies, focusing on SCEs. Battery equalizers extract energy from the most charged cell of a battery pack and either dissipate or transfer it to a less-charged cell. The first method is known as passive balancing and the second as active balancing. Passive balancing is relatively inexpensive and

Oviedo Siembra Talento program of the Oviedo City Council and by the Government of Asturias under project IDI/2018/000188 and FEDER funds. 
easy to implement, although dissipating the excessive energy makes it inefficient. Due to this, recent research efforts are focused on active balancing methods. Methods for active balancing can be classified according to different criteria, as the connections between the cells (cell-to-cell, pack-to-cell, cell-to-pack...) or according to the circuit topology (shunting, shuttling or energy conversion methods) [6], [10]. Shunting methods transfer the energy from one cell to another without any external energy storage device, unlike shuttling methods that use external energy storage devices, e.g. capacitors, inductors or other batteries. The so-called energy conversion methods [6] use isolated converters for equalizing the cells. This solution is the most expensive among them and often used to balance packs of cells, while the other two are more suitable to equalize single cells.

Among shuttling active balancing methods, one of the most appealing methods to equalize single cells is the switched capacitor equalizer [17], due to its low cost and simplicity. This cell-to-cell equalizer balances $\mathrm{N}$ cells with $\mathrm{N}-1$ capacitors and $2 \mathrm{~N}$ switches, see Fig. 1a. The switches continuously work with a fixed duty cycle of $50 \%$, alternating between switches "a" and " $b$ " during regular operation of the battery, including the appropiate dead time to protect the switches from shortcircuits. This can be seen in Fig. 1b, where $T_{s}$ is the switching period and $d t$ the dead time. This way, each capacitor is connected half of the switching period in parallel with one cell and the second half with an adjacent cell, transferring energy from the one with the highest voltage to the one with the lowest voltage. This is schematically shown in Fig. 1c assuming VB1 $>$ VB2 $>$ VB3. In the state 1 (in red), B1 charges $\mathrm{C} 12$ and $\mathrm{B} 2$ charges $\mathrm{C} 23$, i.e. they are connected in parallel, and in state 2 (blue), $\mathrm{C} 12$ discharges over B2 and C23 discharges over B3.

Main advantages of this equalizer are that it does not require control, it is fully scalable, cost effective and easy to implement. As a drawback, cells only transfer energy effectively to their adjacent ones, so the energy might need to flow through a large number of cells, which increases the losses and the equalization time [9]. A prototype for a SCE to balance four cells is shown in Fig. 1d, this prototype will be used for the experimental verification of the proposed battery IR estimation method.

The most commonly used switched capacitor equalizers topologies are briefly analyzed in the following paragraphs [9], [17]-[21].

\section{A. Switched-Capacitor Equalizer Topologies}

-Basic switched-capacitor equalizer [17]: Fig. 1. Explained earlier in this section.

-Double-tiered switched-capacitor equalizer [9], [18], [19]:Fig. 2. An extra capacitor bridges the capacitors in the first row, so batteries have two paths to exchange charge, reducing the equalization time. As a drawback, there is a need of adding an extra capacitor to the system, which must withstand the combined voltage of all the capacitors, compromising the scalability of the topology.

-Chain structure using additional switches or capacitors [9]: Fig. 3. Requires four additional switches compared to the double-tiered SCE, top and bottom cells become therefore adjacent, forcing them to exchange energy between them and their adjacent cells only, and not with all the cells in the pack as in the previous case. The scalability of this topology is
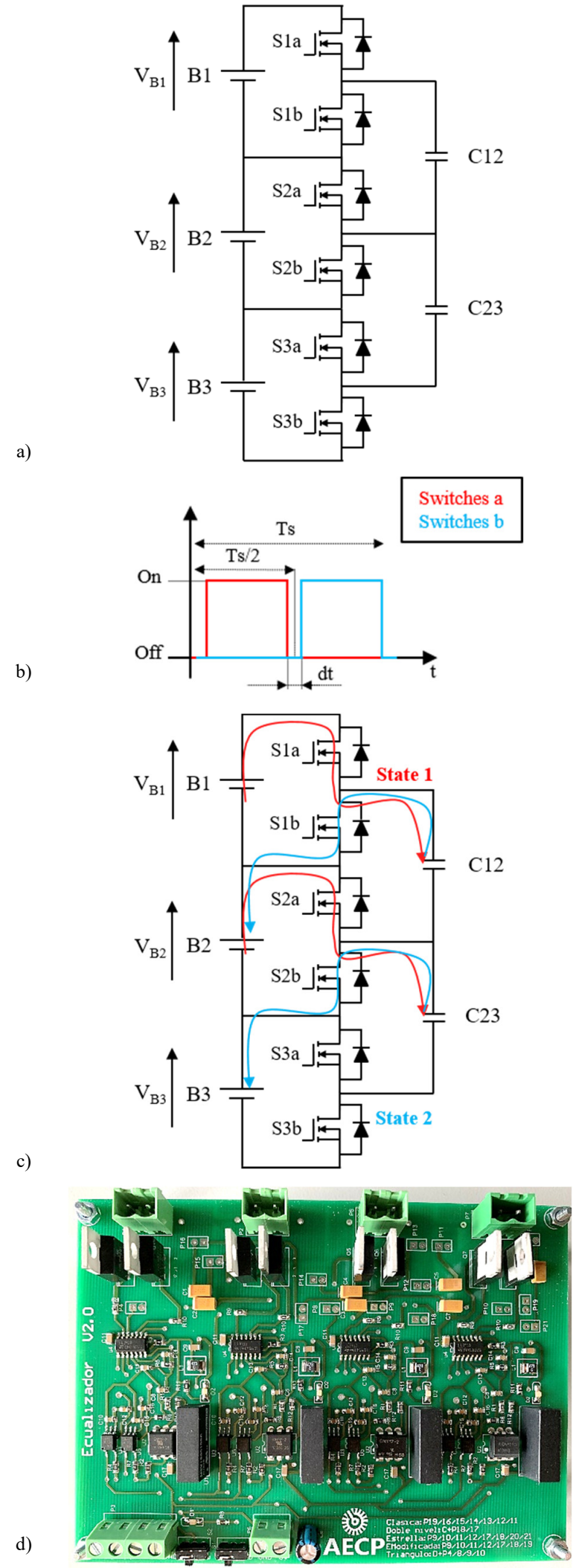

Fig. 1.- Switched capacitor equalizer with 3 batteries, a) schematic with 3 cells, b) switching function, c) paths for the energy at both switching state, d) prototype for balancing up to 4 cells.

compromised as in the previous case since the voltage that the new switches must withstand is the same as the whole battery pack. 
-Star-structured switched-capacitor equalizer [18]: Fig. 4 left. It requires one additional capacitor respect to the classic proposal and connects the capacitors in a star-structure that

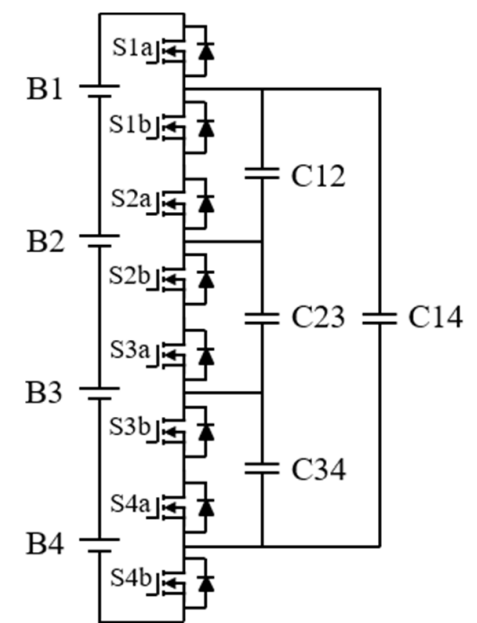

Fig. 2.- Double-tiered switched-capacitor equalizer.

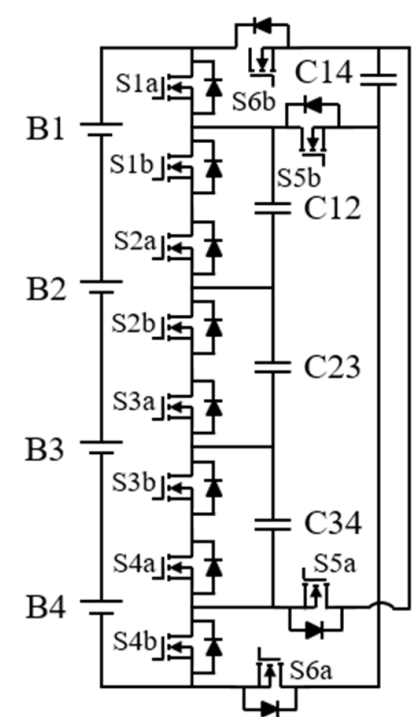

Fig. 3.- Chain structure using additional switches or capacitors.

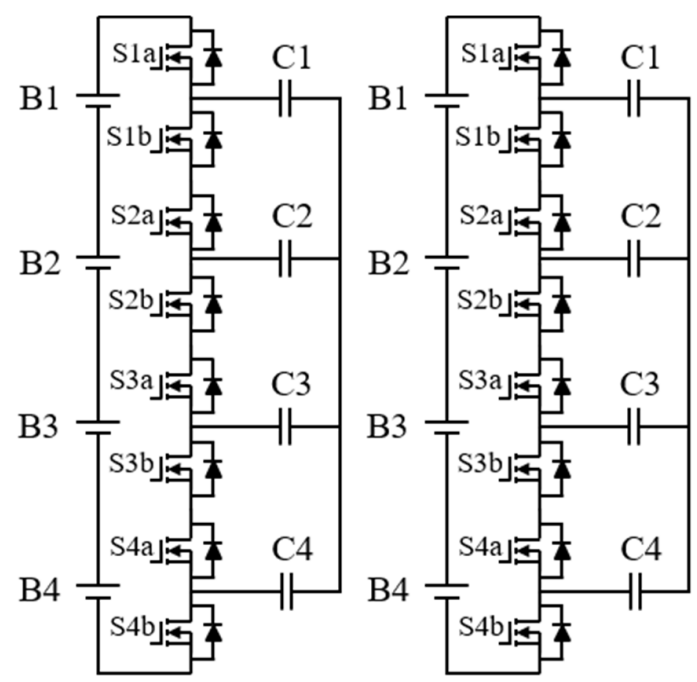

Fig. 4.- Star-structured switched-capacitor equalizer (left) and Starstructured switched-capacitor equalizer with one less capacitor (right). allows interconnection of all the cells at the same time, which decreases the equalization time (making it independent of the initial imbalance status of the string) and efficiency. As a drawback, the scalability is again compromised because the voltage that each capacitor must withstand is different. A variation of this equalizer with one less capacitor can be seen in Fig. 4 right, [18] and [20].

-Delta structured switched-capacitor equalizer [21]: Fig. 5. This equalizer adds capacitors in such a way that there is always one capacitor connecting any two cells, allowing interconnection of all the cells at the same time. As the double-tiered SCE, it maintains the number of switches but increases the number of capacitors (in a higher number) while reducing the equalization time. The voltage that each capacitor must hold is different and dependent on the cells they are bridging.

The previous discussion considered only balancing systems based on switched capacitors. They all have in common the same working principle, being cost-effective solutions easy to implement thanks to the absence of control. The difference in the number of components is related to equalization time, been smaller as the number or components increase. There are more complex systems based in the same principle that combine inductors and capacitors to improve the performance in terms of speed and losses, such as achieving zero current switching [22]. However, the increased difficulty in the design and number of components make them impractical for low cost applications.

\section{EleCtrical EQUivalent BATTERy MODEL}

There are several ways of modeling the battery behavior: electrochemically (complex and difficult to obtain), mathematically (abstract and application-focused) and electrically (electrical equivalent models based on a combination of electrical passive elements). The latter are the most appealing due to their intuitiveness and computational burden [23]. Among electrical models, the Randles [13], [23][25], see Fig. 6, and the Thèvenin [23], [26], [27], see Fig. 7, models, are the most commonly used.

The Randles model (Fig. 6a) is obtained from Electrochemical Impedance Spectroscopy (EIS), a standard methodology for battery characterization. It consists of applying AC voltage to the battery and measure the resulting current to estimate the impedance at different frequencies (Fig. 6b) [24], [25]. Each range of frequencies is dominated

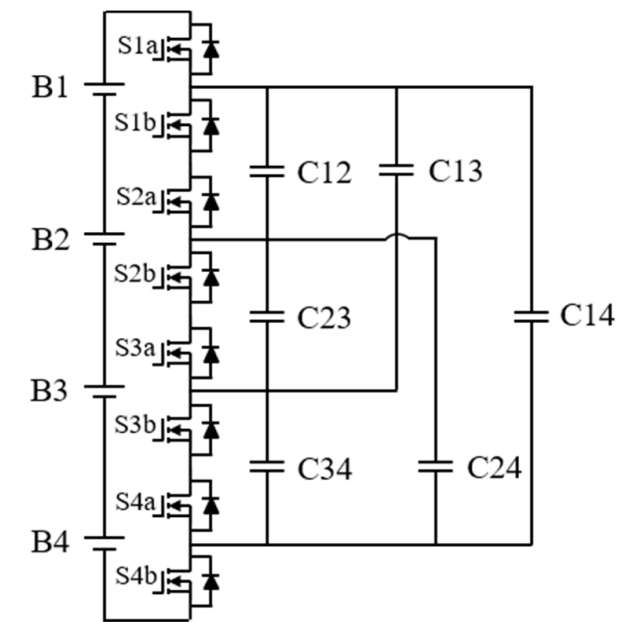

Fig. 5.- Delta-structured switched-capacitor equalizer. 
a)
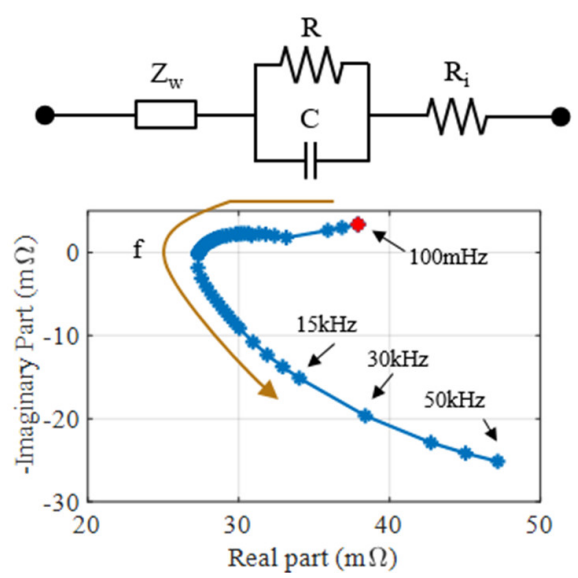

b)

Fig. 6.- Randles equivalent model derived from the Electrochemical Impedance Spectroscopy (EIS) analysis, a) Circuit, b) Nyquist plot.

by different phenomena in the battery (diffusion effect, solidelectrolyte interface (SEI) resistance, metal collectors, etc.) [13].

In Fig. 6a, $Z_{\mathrm{w}}$ represents the Warburg impedance, which accounts for the diffusion phenomena (low frequencies). The $\mathrm{RC}$ circuit corresponds to the electrolyte and SEI resistance on the anode. Finally, $\mathrm{R}_{\mathrm{i}}$ is the IR, point in Fig. $6 \mathrm{~b}$ when the battery impedance changes from capacitive to inductive [13], [24]. Fig. 6b shows the EIS analysis (Nyquist plot) of the LiFePO4 battery used in this paper; the $\mathrm{x}$-axis represents the resistance and the $y$-axis the reactance (sign reversed), while each point in the graph corresponds to a different frequency. The frequency increases following the arrow direction where the red point indicates the smallest analyzed frequency.

On the other hand, Thèvenin model, see Fig. 7a, can be obtained from the battery response to a current step; parameter identification is obtained from the voltage transient response, see Fig. 7b [26]. In Fig. $7 b, R_{i}$ is the cell IR, accounting for the resistance of the contacts, terminals, collectors, electrodes, and electrolyte, while $\mathrm{R}_{\mathrm{D}}$ and $\mathrm{C}_{\mathrm{D}}$ model the dynamic response, resulting from the effect of diffusion and charge transportation. Finally, $\mathrm{C}_{\mathrm{SOC}}$ models the battery

a)
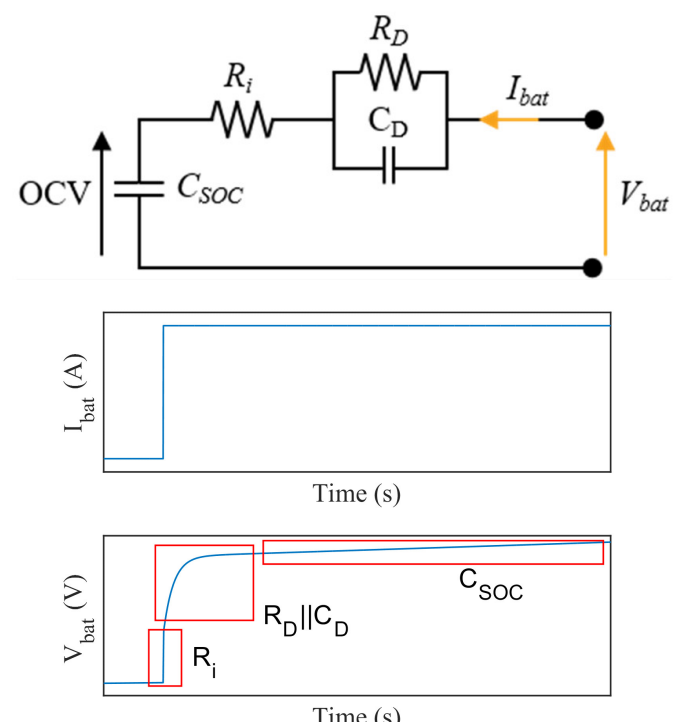

b)

Fig. 7.- a) Thèvenin equivalent model of a battery, and b) response of $a$ battery to a current step. capacity, $\mathrm{C}_{\mathrm{SOC}}$ voltage representing the battery Open Circuit Voltage (OCV) [23], [27]. The transfer function of this model is shown in (1). The first term on the right hand side of (1) corresponds to the IR, Ri, and is obtained from the initial response to the current step, see Fig. $7 \mathrm{~b}$. The second term on the right hand side of (1) is the dynamic RC circuit, a firstorder system corresponding to the exponential part of the voltage variation, see Fig. 7b. The last term on the right hand side of (1) is $\mathrm{C}_{\mathrm{SOC}}$, a pole at the origin, which accounts for the continuously increasing slope in the voltage in Fig. $7 \mathrm{~b}$ due to a constant current.

$$
G(s)=\frac{V_{b a t}(s)}{I_{b a t}(s)}=R_{i}+\frac{R_{D}}{1+R_{D} C_{D} s}+\frac{1}{s} C_{S O C}
$$

Among these models, the Thèvenin one is the most appropriate for battery parameter identification using a SC equalizer, since the process for extracting the parameters involved in (1) (i.e. step response) are similar to the steps produced in the battery as a result of the SC switching.

\section{BATTERy PARAMETER IDENTIFICATION BASED ON SC EQUALIZERS}

This section presents the proposed method for battery IR estimation using signals produced by the SCE operation. A simplified scheme of an SCE is presented in Fig. 8a, where the battery and SCE parameters are shown in Table I. The circuit is connected at the instant $t_{i}$, and the waveforms resulting from this connection are shown in Fig. 8b, which resemble SCE waveforms. Note that applying step voltages is analogous to applying step currents from the point of view of battery parameter estimation [26].

Before the switch connection there is no current circulation, so the voltage measured ( $V_{b a t}$ in Fig. $\left.8 \mathrm{a}\right)$ is the $\mathrm{OCV}$ (the voltage in the capacitor $\mathrm{C}_{\mathrm{SOC}}$ ). After the switch

TABLE I. BATTERY MODEL PARAMETERS

\begin{tabular}{|c|c||c|c|}
\hline Parameter & Value & Parameter & Value \\
\hline $\mathrm{R}_{\mathrm{i}}$ & $50 \mathrm{~m} \Omega$ & $\mathrm{CSOC}_{\mathrm{C}}$ & $19 \mathrm{kF}$ \\
\hline $\mathrm{R}_{\mathrm{D}}$ & $6.7 \mathrm{~m} \Omega$ & $\mathrm{C}_{\mathrm{EQ}}$ & $22 \mu \mathrm{F}$ \\
\hline $\mathrm{C}_{\mathrm{D}}$ & $48 \mathrm{~F}$ & & \\
\hline
\end{tabular}

a)
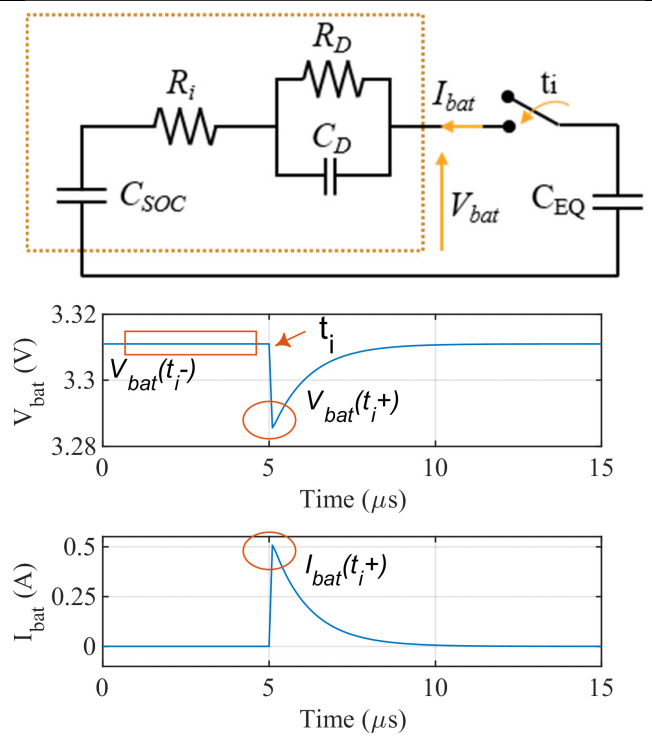

Fig. 8.- a) Simplification of the SCE, modeling the battery as a first order Thèvenin model, and b) voltage and current waveforms of the SCE. 
connection, there is current flowing from/to the battery and consequently a voltage drop in the battery IR, $R_{i}$, exists. Therefore, $R_{i}$ can be obtained from (2). $V_{b a t}\left(t_{i}+\right)$ and $I_{b a t}\left(t_{i}+\right)$ are the voltage and current right after the connection instant $\left(t_{i}\right)$, see Fig. 8b, while $\mathrm{V}_{b a t}\left(t_{i^{-}}\right)$is the OCV (see Fig. 8b).

$$
R_{i}=\frac{\left|V_{b a t}\left(t_{i}-\right)-V_{b a t}\left(t_{i}+\right)\right|}{\left|I_{b a t}\left(t_{i}+\right)\right|}
$$

In case the battery is being charged or discharged, the method is similarly applied with the exception the current in Fig. $8 \mathrm{~b}$ will include this charging/discharging current. In this case, a more general equation, (3) should be used. $I_{b a t}\left(t_{i^{-}}\right)$is the current before the commutation, in this case the current been charging/discharging the battery. The absolute value allows, as in (2), the equation to be used for both charging and discharging. The results remain unchanged.

$$
R_{i}=\frac{\left|V_{b a t}\left(t_{i}-\right)-V_{b a t}\left(t_{i}+\right)\right|}{\left|I_{b a t}\left(t_{i}+\right)-I_{b a t}\left(t_{i}-\right)\right|}
$$

The limitations of the method can be extracted directly from (3): once the batteries are equalized, there is no voltage difference among them, nor equalization current, meaning that $R_{i}$ cannot be estimated this way.

\section{A. Effect of inductive parasitic components}

As it will be seen in section $\mathrm{V}$, the circuitry has some unavoidable parasitic inductances due to e.g. cabling that affect the waveforms shown in Fig. 8b. This effect can be simulated by adding a small inductor (an inductor of $0.1 \mathrm{nH}$ has been used to emulate this effect) in series with CEQ in Fig. 8a. The resulting waveforms are shown in Fig. 9. The orange waveform represents the response of the battery's voltage and current when the inductor is added to the circuit, in comparison with the blue waveforms that show the ideal case.

Since $V_{b a t}$ is measured at the battery terminals, the existence of this parasitic inductor does not affect the estimation of the IR. Equation (3) can be rewritten as (4), where $\min \left(V_{b a t}\right)$ and $\max \left(I_{b a t}\right)$ correspond to the peak values for current and voltage, respectively, right after $t_{i}$. These values are preferred since these points are easier to select and measure, while providing a high signal-to-noises ratio.

$$
R_{i}=\frac{\left|V_{b a t}\left(t_{i}-\right)-\min \left(V_{b a t}\right)\right|}{\left|\max \left(I_{b a t}\right)-I_{b a t}\left(t_{i}-\right)\right|}
$$

\section{B. Battery Temperature Estimation}

It is generally expected [11], [13], [15] that the battery resistance decreases as temperature increases at low
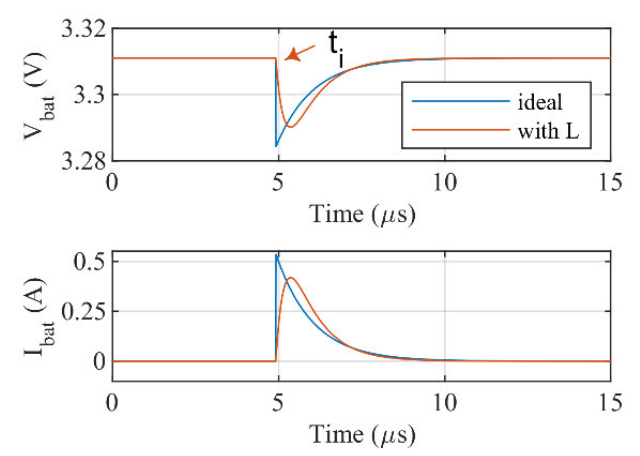

Fig. 9.- SCE with two batteries and one capacitor. frequencies. In this region, the electrolyte and SEI dominate the behavior of the battery and follows the Arrhenius law [13]. However, it must be noted that the proposed method estimates the IR, $R_{i}$ in Fig. 8, which is dominated by the metal collectors and leads [27], which resistances increase as temperature does [11], [15]. Hence, IR can be modeled as a linear function of the battery temperature (5), provided that the metallic part of the battery dominates the response. $R_{b a t}$ is the battery resistance $\left(R_{i}\right)$ at the room temperature $\left(T_{o}\right), T_{b a t}$ is the battery temperature and $\alpha_{b a t}$ is the temperature coefficient; $R_{\text {batn } 0}$ and $\alpha_{b a t}$ can be measured during a commissioning process. The battery temperature is finally estimated from (6).

It is finally noted that although the method proposed in this paper is evaluated for the classical topology, see Fig. 1a, it can be extended to any other switched-capacitor topology, see section II-A.

$$
\begin{gathered}
R_{b a t}=R_{b a t 0}\left(1+\alpha_{b a t}\left(T_{b a t}-T_{0}\right)\right) \\
T_{b a t}=\frac{R_{b a t}-R_{b a t 0}}{R_{b a t 0} \alpha_{b a t}}+T_{0}
\end{gathered}
$$

\section{Simulations}

A SCE with two cells was implemented in Matlab/Simulink, see Fig. 10. The equalizer main parameters are shown in Table II. Cells are implemented using the battery model from Simscape Electrical toolbox, with $\mathrm{LiFePO}_{4}$ battery equivalent parameters. A $30 \%$ difference in SOC between batteries is set as initial condition: the most charged battery has an OCV of $3.312 \mathrm{~V}$ and the less charged one has an OCV of $3.284 \mathrm{~V}$.

Fig. 11a shows the voltage and current of the most charged battery (B1 in Fig. 10) when it is connected in parallel to the balancing capacitor at $\mathrm{t}=140 \mu \mathrm{s}$. Voltage and current waveforms are seen to be in good agreement with the ones obtained with the Thèvenin model, see Fig. $8 \mathrm{~b}$. The estimated internal battery resistance (2) is $\approx 50 \mathrm{~m} \Omega$, which matches $R_{i}$ defined in Table II and included in the battery model for the simulation. Same results are obtained if the parasitic inductor

TABLE II. EQUALIZER AND BATTERY CHARACTERISTIC PARAMETERS.

\begin{tabular}{|c|c|}
\hline Parameter & Value \\
\hline Nominal battery voltage & $3.2 \mathrm{~V}$ \\
\hline Nominal current & $3.2 \mathrm{~A}$ \\
\hline Maximum charge current & $1 \mathrm{C}$ \\
\hline Maximum discharge current & $3 \mathrm{C}$ \\
\hline Battery capacity & $3300 \mathrm{mAh}$ \\
\hline Equalizer capacitor & $22 \mu \mathrm{F}$ \\
\hline Internal resistance $\left(R_{i}\right)$ & $50 \mathrm{~m} \Omega$ \\
\hline
\end{tabular}

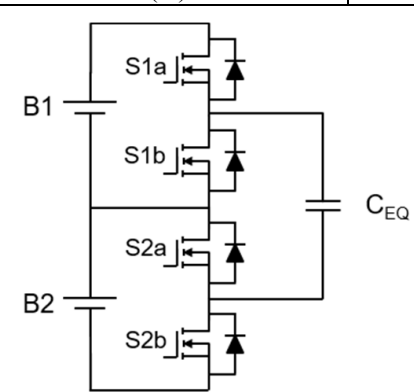

Fig. 10.- SCE with two batteries and one capacitor. 

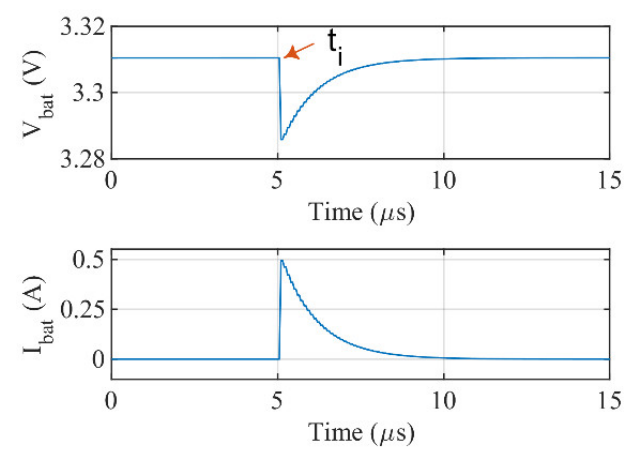

a)
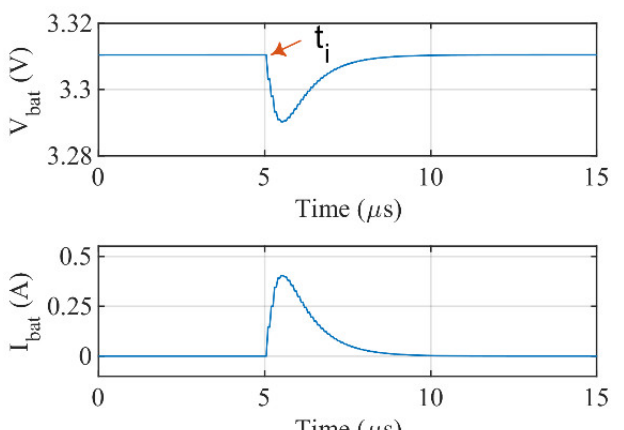

b) Time $(\mu \mathrm{s})$
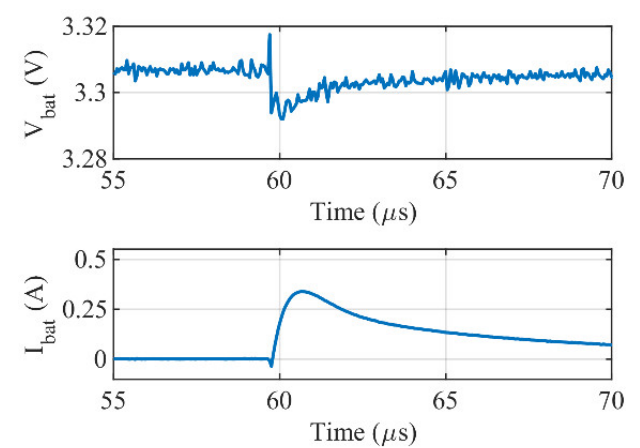

Fig. 11.- Resulting waveform from the equalizer, a) Simulink, ideal case, b) Simulink, case with the parasitic inductor, c) Experimental results (fs $=20 \mathrm{kHz}, \mathrm{T}=20^{\circ} \mathrm{C}$, SOC differences $=30 \%$ ).

is added in series with $C_{e q}$ (Fig. 11b), as it was explained in section IV-A.

\section{EXPERIMENTAL RESULTS}

The SCE shown in Fig. 1c was used to carry out the experimental results. A two-cell arrangement has been used to be consistent with the simulation results shown in Section V. Current and voltage waveforms were measured with a Yokogawa 701932 current probe and with a Yokogawa 701938 voltage probe, respectively. Signals were captured with a Yokogawa 720250 12-bit 2-channel module plugged into a Yokogawa DL850 ScopeCoder. Parameters of the battery and SCE are shown in Table II. The $\mathrm{LiFePO}_{4}$ battery used in this work is shown in Fig. 12. Voltage measurement is performed at battery terminals. Battery voltage and current in one switching cycle are shown in Fig. 11c. It can be seen that the current has a smoother response than in the ideal simulation (Fig. 11a), and similar to Fig. 11b, due to inductive parasitic components present in the actual system, as it was previously explained in section IV-A, hence (4) is used to estimate the IR.

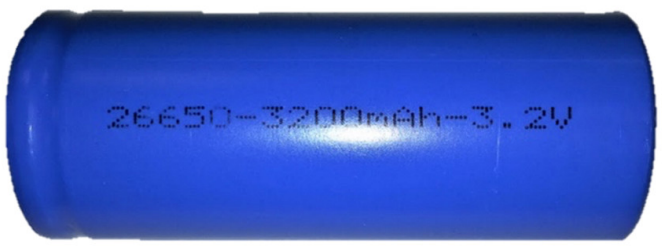

Fig. 12.- $\mathrm{LiFePO}_{4}$ battery.

\section{A. Resistance Variation With Switching Frequency}

Fig. 13 shows the estimated battery resistance for a set of experimental data captured with the SCE working at $10 \mathrm{kHz}$, $20 \mathrm{kHz}$ and $30 \mathrm{kHz}$; the mean value of the estimated battery resistance is shown in red.

The mean value at all the frequencies of the estimated resistances shown in Fig. 13 is similar at all the frequencies, since the resistance being estimated is $\mathrm{R}_{\mathrm{i}}$, which depends on the voltage/current at the switching instant, which is independent of the SCE switching frequency. It is also noted that $\mathrm{SOC}, \mathrm{SOH}$ or temperature time constants are significantly larger than battery resistance estimation time [28], meaning that averaging the measurements for a certain period could be an acceptable and easy solution to reject measurement noise. Experimental results are repeated with another battery (see Fig. 14) with the same characteristics, to show the replicability of the methodology. It is shown that $R_{i}$ mean value is independent of the switching frequency. However, absolute value of $R_{i}$ is different: for the first battery the mean value of $R_{i}$ is $\approx 40 \mathrm{~m} \Omega$, while for the second one is $\approx 30 \mathrm{~m} \Omega$. This was expected due to differences among batteries existing in practice [6], [7].

\section{B. Resistance Variation With Temperature}

Fig. 15 shows the estimated IR for three different batteries as the temperature increases. The batteries are slowly heated (for around 45 minutes, see Fig. 16) up to $65^{\circ} \mathrm{C}$ while

a)
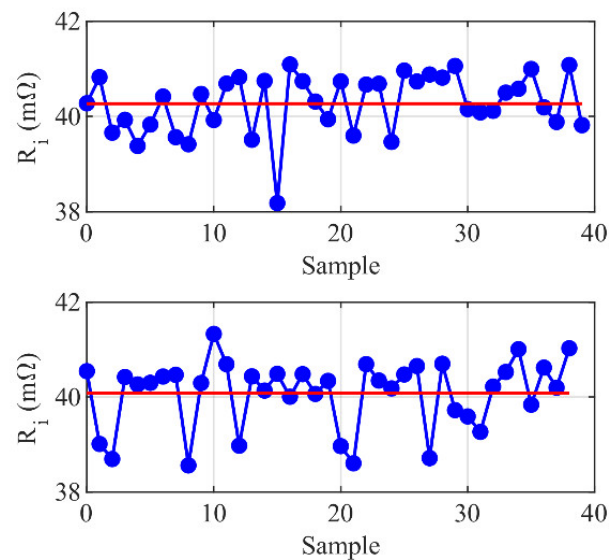

b)

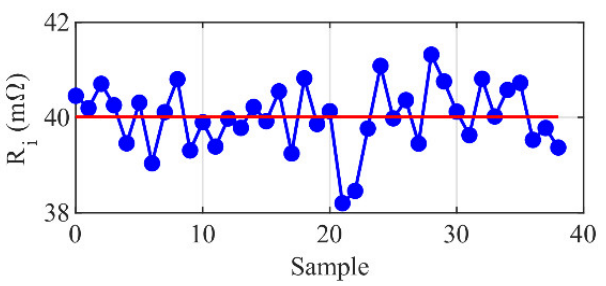

Fig. 13.- Battery 1 IR estimation using the experimental data collected from the equalizer (blue) and mean value of the estimated resistance (red): a) $10 \mathrm{kHz}$, b) $20 \mathrm{kHz}$, and c) $30 \mathrm{kHz}$. 

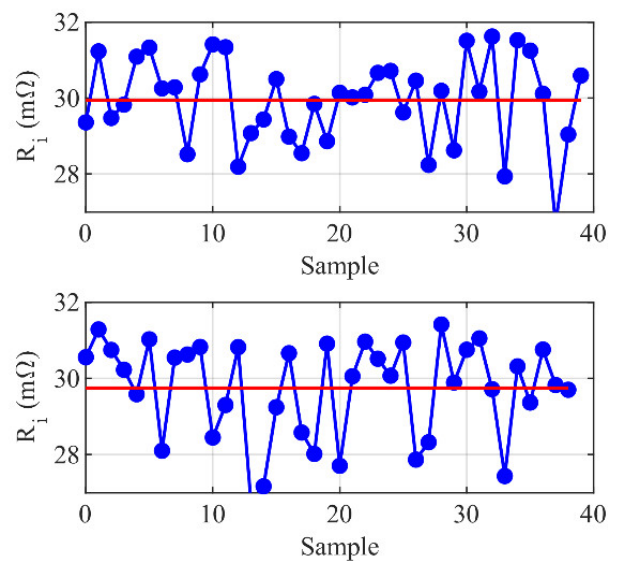

b)

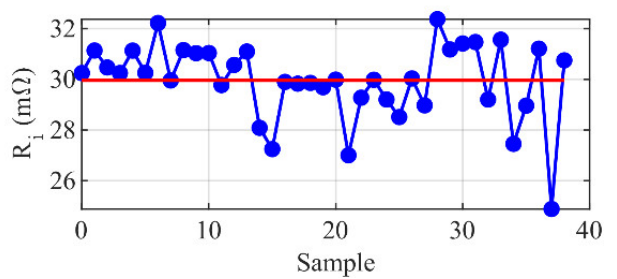

Fig. 14.- Battery 2 IR estimation using the experimental data collected from the equalizer (blue) and mean value of the estimated resistance (red), a) $10 \mathrm{kHz}$, b) $20 \mathrm{kHz}$, c) $30 \mathrm{kHz}$.

capturing current, voltage and temperature. Temperature of the batteries are monitored using LM35 temperature sensors [29], placed on the surface of the battery. It can be observed from Fig. 15 how the battery resistance increases almost linearly with temperature for all tested batteries.

It can be observed from Fig. 15 that, although there is an offset among IRs, the rate of variation of IR with temperature is similar for all batteries under test. Offsets present among cells will not affect the accuracy of the proposed method because the battery temperature will be estimated from variations of the resistance with temperature respect to the room temperature resistance $\left(R_{\text {bat } 0}\right)$ as seen in (6).

Fig. 17 shows the measured and estimated temperature using (6). First, the slope that best fits the temperature

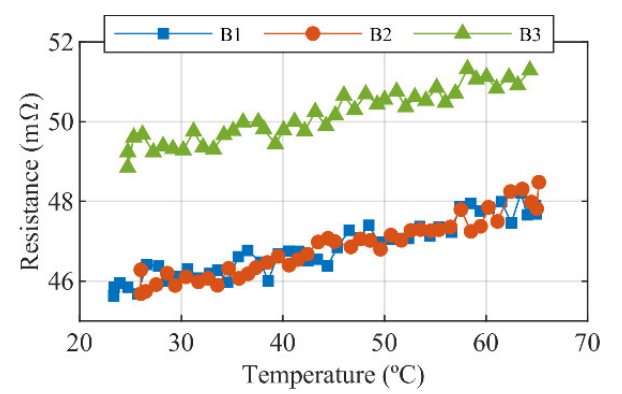

Fig. 15.- Battery resistance vs. battery temperature for different batteries.

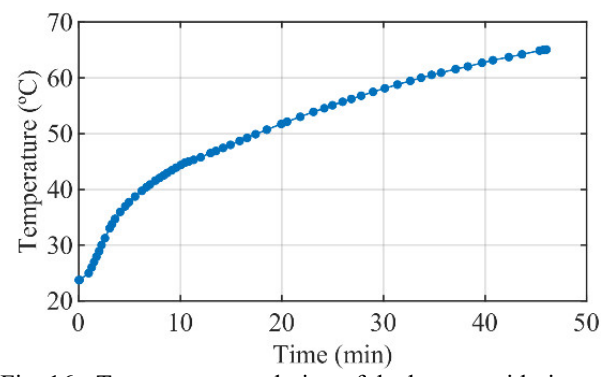

Fig. 16.- Temperature evolution of the battery with time.

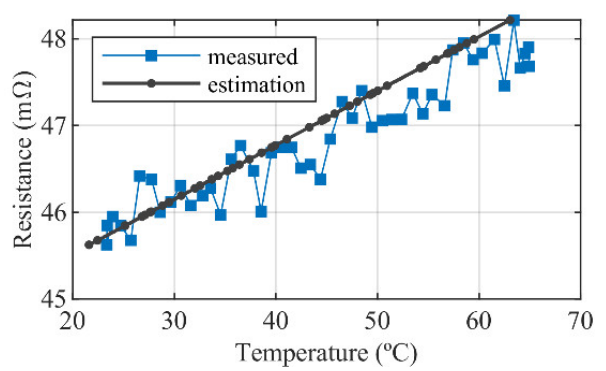

a)

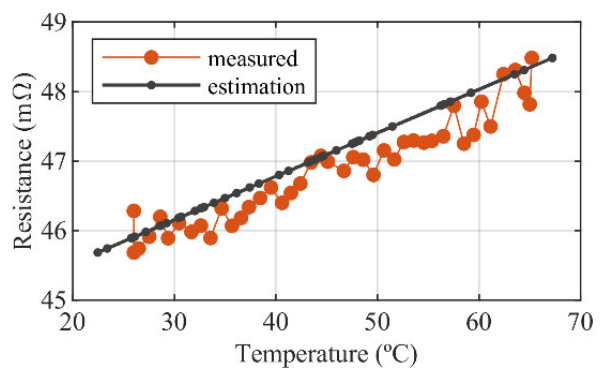

b)

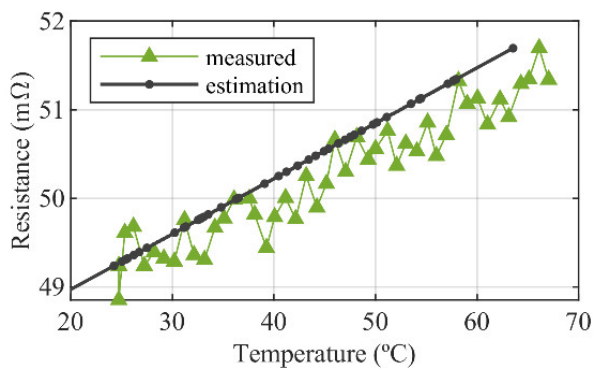

Temperature $\left({ }^{\circ} \mathrm{C}\right)$
Fig. 17.- Measured and estimated temperatures for three different batteries, a)-c) B1-B3.

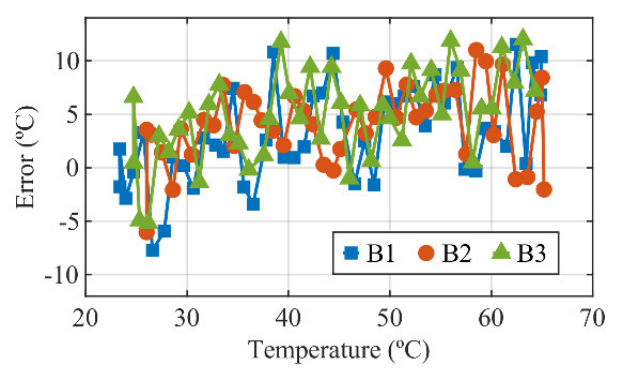

Fig. 18.- Error between measured and estimated temperature.

variation for each of the three batteries was obtained (see table III), then, the average value of this slope $\left(\alpha_{\text {bat }}=16.72\right.$ ${ }^{\circ} \mathrm{C} / \mathrm{m} \Omega$ ) is used to estimate the temperature for all batteries under test. The temperature estimation error for the three batteries analyzed is shown in Fig. 18; the temperature estimation error is seen to be less than $\approx 12^{\circ} \mathrm{C}$ for any point, with a mean value of $4^{\circ} \mathrm{C}$ and a standard deviation of $4.11^{\circ} \mathrm{C}$. Due to this difference, it is important to analyze more than one point every time, as seen in Fig. 13 and Fig. 14, so the conclusions in terms of temperature are valid.

TABLE III: THERMAL COEFICIENTS FOR THE DIFFERENT CELLS EVALUATED

\begin{tabular}{|c|c|}
\hline Battery & $\begin{array}{r}\text { Thermal coefficient } \boldsymbol{\alpha}_{\text {bat }} \\
\left({ }^{\mathbf{o}} \mathbf{C} / \mathbf{m} \mathbf{\Omega}\right)\end{array}$ \\
\hline 1 (blue in Fig. 17) & 17.54 \\
\hline 2 (orange in Fig. 17) & 15.98 \\
\hline 3 (green in Fig. 17) & 16.65 \\
\hline Average & 16.72 \\
\hline
\end{tabular}




\section{CONCLUSIONS}

This paper proposes the use of signals naturally produced by SCEs to estimate the battery IR. The method operates without interfering with the regular operation of both the equalizer and battery. Experimental results have been provided to demonstrate the viability of the proposed method. The method is valid for a wide range of switching frequencies. IR estimated can be used to estimate battery's temperature.

\section{ACKNOWLEDGMENT}

The authors wish to acknowledge the support and motivation provided by the University of Oviedo, Spain and Electrotécnica Industrial y Naval, S.L. (ELINSA), Spain.

\section{REFERENCES}

[1] C. G. Moral, D. F. Laborda, L. S. Alonso, J. M. Guerrero, D Fernández, C. Rivas and D. Reigosa, "Battery internal resistance estimation using a battery balancing system based on switched capacitors," IEEE Energy Conversion Congress and Exposition (ECCE), Baltimore, MD, USA, pp. 2516-2522, Sept. 2019.

[2] D. Anseán, M. González, V. M. García, J. C. Viera, J. C. Antón and C. Blanco, "Evaluation of $\mathrm{LiFePO} 4$ batteries for electric vehicle applications," IEEE Transaction on Industrial Application, vol. 51, no. 2, pp. 1855-1863, March-April 2015.

[3] Z. Miao, L. Xu, V. R. Disfani and L. Fan, "An SOC-based battery management system for microgrids," IEEE Transactions on Smart Grid, vol. 5, no. 2, pp. 966-973, March 2014.

[4] J.P. Fellner, G.J. Loeber, S.P. Vukson, C.A. Riepenhoff, "Lithium-ion testing for spacecraft applications," Journal of Power Sources, vol. 119-121, pp. 911-913, June 2003.

[5] G. Pistoia, "In battery operated devices and systems," Elsevier, Amsterdam, 2009.

[6] J. Cao, N. Schofield and A. Emadi, "Battery balancing methods: A comprehensive review," IEEE Vehicle Power and Propulsion Conference, Harbin, pp. 1-6, Sept. 2008.

[7] W. F. Bentley, "Cell balancing considerations for lithium-ion battery systems," The Twelfth Annual Battery Conference on Applications and Advances, Long Beach, CA, USA, 1997, pp. 223-226.

[8] S. W. Moore and P. J. Schneider, "A review of cell equalization methods for lithium ion and lithium polymer battery systems," SAE Technical Paper, March 2001.

[9] M. Kim, C. Kim, J. Kim and G. Moon, "A Chain structure of switched capacitor for improved cell balancing speed of Lithium-Ion batteries," IEEE Transactions on Industrial Electronics, vol. 61, no. 8, pp. 39893999, Aug. 2014.

[10] H. Rahimi-Eichi, U. Ojha, F. Baronti and M. Chow, "Battery management system: An overview of its application in the smart grid and electric vehicles," IEEE Industrial Electronics Magazine, vol. 7, no. 2, pp. 4-16, June 2013

[11] A. E. Mejdoubi, H. Gualous, H. Chaoui and G. Alcicek, "Experimental investigation of calendar aging of lithium-ion batteries for vehicular applications," EMC Conference, Turkiye, Ankara, pp. 1-5, Sept. 2017

[12] R. R. Richardson, P. T. Ireland, D. A. Howey, "Battery internal temperature estimation by combined impedance and surface temperature measurement," Journal of Power Sources, vol. 265, pp 254-261, Nov. 2014.

[13] N. S. Spinner, C. T. Love, S. L. Rose-Pehrsson, S. G. Tuttle, "Expanding the Operational Limits of the Single-Point Impedance
Diagnostic for Internal Temperature Monitoring of Lithium-ion Batteries," Electrochimica Acta, vol. 174, pp. 488-493, August 2015.

[14] C. G. Moral, D. Fernandez, J. M. Guerrero, D. Reigosa and F. Briz, "Thermal monitoring of LiFePO4 batteries using switching harmonics," IEEE Energy Conversion Congress and Exposition (ECCE), Portland, OR, pp. 2734-2740, Sept. 2018.

[15] J. P. Schmidt, S. Arnold, A. Loges, D. Werner, T. Wetzel, E. IversTiffee, "Measurement of the internal cell temperature via impedance: Evaluation and application of a new method," Journal of Power Sources, vol. 243, pp. 110-117, Dec. 2013.

[16] D. Ansean, M. Gonzalez, J. C. Viera, V. M. Garcia, J. C. Alvarez and C. Blanco, "Electric vehicle Li-Ion battery evaluation based on internal resistance analysis," IEEE Vehicle Power and Propulsion Conference (VPPC), Coimbra, pp. 1-6, Oct. 2014.

[17] C. Pascual and P. T. Krein, "Switched capacitor system for automatic series battery equalization," Proc. IEEE 1997 Applied Power Electronics Conference, pp. 848-854, Feb. 1997.

[18] Y. Ye, K. W. E. Cheng, Y. C. Fong, X. Xue and J. Lin, "Topology, modeling, and design of switched-capacitor-based cell balancing systems and their balancing exploration," IEEE Transactions on Power Electronics, vol. 32, no. 6, pp. 4444-4454, June 2017.

[19] A. C. Baughman and M. Ferdowsi, "Double-tiered switched-capacitor battery charge equalization technique," IEEE Transactions on Industrial Electronics, vol. 55, no. 6, pp. 2277-2285, June 2008.

[20] Y. Shang, N. Cui, B. Duan and C. Zhang, "Analysis and optimization of star-structured switched-capacitor equalizers for series-connected battery strings, " IEEE Transactions on Power Electronics, vol. 33, no. 11, pp. 9631-9646, Nov. 2018.

[21] Y. Shang, C. Zhang, N. Cui and C. C. Mi, "A delta-structured switchedcapacitor equalizer for series-connected battery strings," IEEE Transactions on Power Electronics, vol. 34, no. 1, pp. 452-461, Jan. 2019.

[22] Y. Yuanmao, K. W. E. Cheng and Y. P. B. Yeung, "Zero-current switching switched-capacitor zero-voltage-gap automatic equalization system for series battery string," IEEE Transactions on Power Electronics, vol. 27, no. 7, pp. 3234-3242, July 2012.

[23] Min Chen and G. A. Rincon-Mora, "An accurate electrical battery model capable of predicting runtime and I-V performance," IEEE Transactions on Energy Conversion, vol. 21, no. 2, pp. 504-511, June 2006.

[24] B. Pattipati, C. Sankavaram and K. Pattipati, "System Identification and Estimation Framework for Pivotal Automotive Battery Management System Characteristics," IEEE Transactions on Systems, Man, and Cybernetics, Part C (Applications and Reviews), vol. 41, no. 6, pp. 869-884, Nov. 2011.

[25] S. Buller, M. Thele, E. Karden, R. W. D. Doncker, "Impedance-based non-linear dynamic battery modeling for automotive applications," Journal of Power Sources, vol. 113, no. 2, pp. 422-430, Jan. 2003.

[26] B. Schweighofer, K. M. Raab and G. Brasseur, "Modeling of high power automotive batteries by the use of an automated test system," IEEE Transactions on Instrumentation and Measurement, vol. 52, no. 4, pp. 1087-1091, Aug. 2003.

[27] M. A. Roscher, D. U. Sauer, "Dynamic electric behavior and opencircuit-voltage modeling of LiFePO4-based lithium ion secondary batteries," Journal of Power Sources, vol. 196, pp. 331-336, Jan. 2011.

[28] Yuan Zou, Xiaosong Hu, Hongmin Ma, Shengbo Eben Li, "Combined State of Charge and State of Health estimation over lithium-ion battery cell cycle lifespan for electric vehicles," Journal of Power Sources, Volume 273, pp. 793-803, Jan. 2015.

[29] Texas Instruments, LM35 Precision Centigrade Temperature Sensors datasheet, August, 1999. Revised Dec, 2017 